\title{
PENDEKATAN BERMAIN UNTUK MENINGKATKAN HASIL BELAJAR MENGGIRING SEPAKBOLA DI SEKOLAH DASAR
}

\author{
Asep Akbaruddin \\ STKIP Subang \\ Asep.akaruddin@gmail.com
}

\begin{abstract}
This research aims to improve learning outcomes dribbling on the game of football by using the approach play. The subjects were all students of class $V$ SDN Kertawaluya III amounted to 24 people. Research methods using action research methods to design Kemmis and Taggart. The results obtained in the pre-cycle is an average value of 64.58 students with students who have not completed as much as $62.5 \%$, whereas that have been completed as much as $37.5 \%$. In the first cycle the average value of students increased to 68.75 with students who have not completed as much as $25 \%$, while that has been completed as much as $75 \%$. And the second cycle of the average value of students increased to 74.17 with students who have not completed as much as $12.5 \%$, while that has been completed as much as $87.5 \%$. Based on these results it can be concluded that by using the approach of learning outcomes dribble play in the game of football is increasing. That way physical education teachers can use the approach to play in the teaching process.
\end{abstract}

Keywords: Learning Outcomes, Dribbling Ball, Playing Approach

\begin{abstract}
ABSTRAK
Penelitian ini bertujuan untuk meningkatkan hasil belajar menggiring bola pada permainan sepak bola dengan menggunakan pendekatan bermain. Subjek penelitian ini adalah seluruh siswa kelas V SDN Kertawaluya III berjumlah 24 orang. Metode penelitian menggunakan metode penelitian tindakan dengan desain Kemmis dan Taggart. Hasil penelitian yang diperoleh adalah pada pra siklus rata-rata nilai siswa sebesar 64,58 dengan siswa yang belum tuntas sebanyak $62,5 \%$, sedangkan yang sudah tuntas sebanyak $37,5 \%$. Pada siklus I rata-rata nilai siswa meningkat menjadi 68,75 dengan siswa yang belum tuntas sebanyak $25 \%$, sedangkan yang sudah tuntas sebanyak $75 \%$. Dan pada siklus II rata-rata nilai siswa meningkat menjadi 74,17 dengan siswa yang belum tuntas sebanyak $12,5 \%$, sedangkan yang sudah tuntas sebanyak $87,5 \%$. Berdasarkan hasil tersebut dapat disimpulkan bahwa dengan menggunakan pendekatan bermain hasil belajar menggiring bola pada permainan sepak bola meningkat. Dengan begitu guru pendidikan jasmani dapat menggunakan pendekatan bermain dalam proses mengajarnya.
\end{abstract}

Kata Kunci: Hasil Belajar, Menggiring Bola, Pendekatan Bermain 
A. Pendahuluan

Pendekatan

bermain

merupakan salah satu upaya yang dapat dilakukan oleh para guru penjas agar proses pembelajaran penjas dapat mencerminkan DAP (Developmentally Appropriate Practice), praktek sesuai dengan tahap pengembangan yang artinya bahwa tugas ajar yang disampaikan harus memperhatikan perubahan kemampuan atau kondisi anak dan dapat membantu mendorong perubahan tersebut. Tidak sedikit guru penjas yang terjebak dalam ketergantungan penyajian materi pembelajaran kepada hal-hal yang sifatnya prinsip dan standar serta harus sesuai dengan kurikulum yang sudah ditentukan. Sehingga tidak sedikit pula guru penjas dilanda kebosanan, yang selanjutnya kondisi ini berdampak pada pembentukan dan pengembangan siswa.

Pelaksanaan pendekatan
bermain merupakan salah satu
alternatif atau solusi dalam
menciptakan suasana belajar yang
lebih efektif, dan modifikasi
pendekatan bermain merupakan

implementasi yang sangat berintegrasi dengan aspek pendidikan lainnya. Pengertian dan makna pendekatan bermain dalam pendidikan jasmani adalah pendekatan bermain dan peralatan, guru dapat mengurangi atau menambah tingkat kompleksitas dan kesulitan tugas ajar dengan cara memodifikasi yang digunakan untuk melakukan skill itu, misalnya : berat-ringannya, besar-kecilnya, tinggi-rendahnya, panjangpendeknya pendekatan bermain dan peralatan yang digunakan. (Lutan dan Suherman, 2000: 69).

Selanjutnya Robert Koger (2007:51) menerangkan bahwa : Menggiring bola (dribbling) adalah metode menggerakan bola dari satu titik ke titik lain di lapangan dengan menggunakan kaki. Bola harus selalu dekat dengan kaki agar mudah dikontrol. Pemain tidak boleh terus menerus melihat bola. Mereka juga harus melihat ke sekeliling dengan kepala tegak agar dapat mengamati situasi lapangan dan mengawasi gerak gerik pemain lainnya.

Sepakbola merupakan cabang olahraga yang 
menggunakan media pembelajaran utamanya berupa bola. Permainan sepak bola merupakan permainan beregu yang memerlukan dasar kerja sama antar sesama anggota regu sebagai salah satu ciri khas dari permainan sepak bola. Hal ini sesuai dengan perkataan Usli (2011: 18) bahwa : "Sepak bola merupakan olahraga beregu, satu regu terdiri dari sebelas orang pemain, tiap-tiap pemain mempunyai peranan masingmasing". Dalam hal ini Richad Hantula (2012:5) mengatakan bahwa : Soccer is the most popular sport in the world. But most people around the globe don't call it soccer. They call it football. People in the United States, however, use football as the name of a different game. So Americans say "soccer" when they mean the game with lots of kicking. Sedangkan K. C. Kelley (2009:9), yang mengatakan bahwa "In a game, each team has 11 players. They move the ball back and forth among themselves, trying to get the ball into the opponent's goal. The goal is 8 yards $(7.3$ meters) wide and 8 feet $(2.4 \mathrm{~m})$ high. The object of the game is to score more goals than the opponent".

Untuk bisa bermain sepak bola dengan baik dan benar para pemain harus menguasai teknikteknik dasar sepak bola. Pemain sepak bola dibekali dengan teknik dasar yang baik, pemain yang memiliki teknik dasar yang baik cenderung bermain sepak bola dengan baik pula.

Dalam penelitian ini teknik dasar yang akan dipelajari yaitu menggiring bola. Menggiring bola pada dasarnya adalah menendang bola secara terputus-putus atau pelan-pelan yang tujuannya adalah untuk mendekati jarak ke sasaran, melewati lawan dan menghambat permainan. Menurut Patricia J Murphy (2008:17), Menendang bola adalah try running with the ball. Maksudnya adalah bahwa menggiring bola juga sering disebut sebagai berjalan dengan bola. To dribble, you have to move the ball with the tops of your feet. Artinya adalah untuk melakukan gerakan menggiring bola, kita harus memindahkan bola dengan menggunakan kaki bagian depan. Menggiring adalah keterampilan 
dasar dalam sepak bola karena semua pemain harus mampu menguasai bola saat sedang bergerak, berdiri, atau bersiap ,melakukan operan atau tembakan. (Miekle, 2003: 1).

Menggiring bola (dribbling) adalah metode menggerakan bola dari satu titik ke titik lain di lapangan dengan menggunakan kaki. Kemudian Luxbache (2004: 47) mengatakan teknik dasar permainan sepak bola tersebut memungkinkan anda untuk mempertahankan bola saat berlari melintasi lawan atau maju keruang yang terbuka. Jadi bola harus terus tetap berada dalam penguasaan kita, maka dari itulah di dalam menggiring bola, kita jangan terus fokus melihat ke arah bola, akan tetapi sesekali harus melihat ke arah sekitar.

Untuk mengetahui sejauh mana pengunaan pendekatan bermain ini terhadap kemampuan siswa dalam meningkatkan hasil belajar sepak bola khususnya teknik dasar menggiring bola, maka penulis akan melakukan penelitian dengan melaksanakan proses pembelajaran dengan menggunakan pendekatan bermain dengan teknik dasar menggiring bola menggunakan media peralatan bola sepak yang telah di modifikasi pula.

Diharapkan dengan adanya modifikasi pendekatan bermain dan media pembelajaran dapat memotivasi siswa agar lebih aktif bergerak, serta dapat mengatasi kompleksitas pembelajaran pola gerak dasar siswa sekolah dasar. Karena permainan merupakan kegiatan yang dirancang dengan aturan sendiri, sehingga dapat memberikan stimulus yang mendekati kenyataan sehari-hari. Dari sinilah dapat dilihat respon yang muncul dan kemudian digunakan sebagai alat evaluasi diri. (Lengkong dan Dwi, 2008: 39). Berdasarkan uraian tersebut, maka yang menjadi tujuan dalam penelitian ini adalah untuk meningkatkan hasil belajar menggiring bola pada siswa SDN Kertawaluya III dengan model pendekatan bermain.

\section{B. Metode Penelitian}

Metode penelitian yang digunakan adalah metode 


Penelitian Tindakan Kelas
(Clasroom Action Research),

denga desain Kemmis dan Taggart.

Setiap tindakan upaya perencanaan tujuan tersebut dirancang dalam suatu unit sebagai suatu siklus. Setiap siklus terdiri dari empat tahapan, yakni

perencanaan tindakan;

pelaksanaan tindakan;

observasi dan imperprestasi; (4) analisis dan refleksi untuk perencanaan siklus berikutnya. Penelitian ini terjadi selama dua siklus, dimana setiap siklus terdiri dari tiga pertemuan/tatap muka.

Pelaksanaan penelitian melibatkan rekan sejawat sebagai kolaborator dan guru kelas sebagai pelaksana tindakan. Hasil akhir dari kegiatan penelitian tindakan adalah meningkatkan hasil belajar khususnya pembelajaran pendidikan jasmani pada materi menggiring bola di SD Negeri Kertawaluya III Semester Genap Tahun Pelajaran 2014 / 2015.

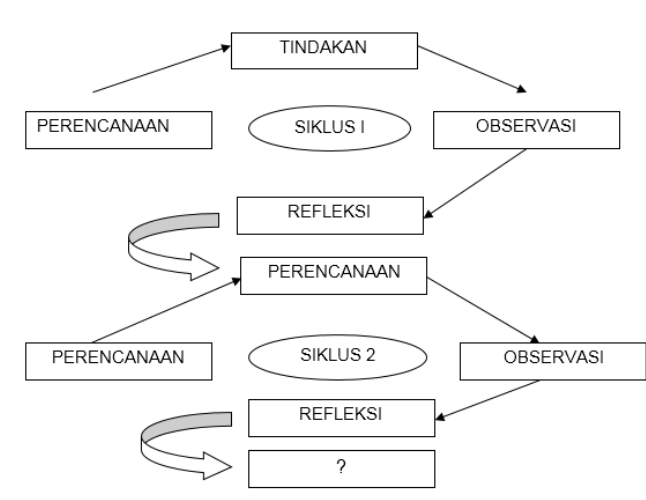

Gambar 1 : Desain Penelitian Tindakan Model Kemmis dan Mc Taggart

Sumber : Arikunto, 2006. h. 97

Subjek dalam penelitian ini adalah semua siswa kelas $\mathrm{V}$ SDN Kertawaluya III yang berjumlah 24 orang (Laki-laki 12 orang dan Perempuan 12 orang). Instrumen yang digunakan dalam penelitian ini adalah tes hasil belajar menggiring bola dalam permainan sepak bola, observasi dan catatan lapangan. Kriteria keberhasilan dalam penelitian ini adalah apabila hasil belajar siswa pada setiap siklusnya mengalami peningkatan, dan secara keseluruhan siswa yang tuntas sudah ada sebanyak $80 \%$.

Analisis data dalam penelitian ini adalah deskriptif kualitatif dan kuantitatif. Data kuantitatif 
membandingkan data tes awal dan hasil tes setelah siklus 1 dan 2 . Sedangkan kualitatif adalah refleksi dalam setiap siklusnya berdasarkan hasil observasi yang terekam dalam catatan lapangan, dokumentasi, dan observasi. Analisis data dilakukan secara deskriptif dengan membandingkan hasil pencapaian dengan indikator keberhasilan.

Data yang dikumpulkan pada setiap kegiatan observasi dari pelaksanaan siklus PTK dianalisis secara deskriptif dengan menggunakan prosentase untuk melihat kecenderungan yang terjadi dalam kegiatan pembelajaran pendidikan jasmani siswa kelas V SDN Kertawaluya III Semester Genap Tahun Pelajaran 2014 / 2015.

\section{C.Hasil Penelitian dan Pembahasan}

\section{Pra Siklus}

Hasil yang diperoleh dari pra siklus adalah Siswa kurang memiliki perhatian dan motivasi dalam pembelajaran menggiring bola dalam permainan sepak bola, karena pembelajaran masih menggunakan motode konvensional dan kurang menggunakan media pembelajaran yang bervariasi.

Saat mengikuti pembelajaran pendidikan jasmani, siswa masih menunjukkan sikap seenaknya sendiri, kurang memperhatikan penjelasan guru, kurang memperhatikan pelajaran dengan sepenuhnya, ada yang berbicara dengan teman, bahkan ada yang bermain sendiri dengan temannya. Guru masih kesulitan menemukan contoh/model pembelajaran yang baik untuk materi menggiring bola dalam permainan sepak bola. Seringkali contoh/demonstarsi yang disampaikan oleh guru melalui peragaan langsung, kurang dapat dicermati oleh siswa secara baik. Dan untuk hasil belajar menggiring bola siswa pada saat pra siklus, penulis akan sajikan dalam bentuk tabel dan diagram sebagai berikut : 


\section{Tabel 1 : Tes Hasil Belajar Menggiring Bola Pra Siklus}

\begin{tabular}{|c|c|c|c|c|c|}
\hline No & Rentang Skor & Nilai & Frekuensi & Porsentase & Kategori \\
\hline 1 & $3-5$ & 60 & 15 & $62,5 \%$ & Kurang \\
\hline 2 & $6-8$ & 70 & 7 & $29,2 \%$ & Cukup \\
\hline 3 & $9-10$ & 80 & 2 & $8,3 \%$ & Baik \\
\hline 4 & $11-12$ & 90 & 0 & $0 \%$ & Baik Sekali \\
\hline \multicolumn{7}{|c|}{ Jumlah } & $\mathbf{2 4}$ & $\mathbf{1 0 0 \%}$ & \multicolumn{2}{c}{} \\
\cline { 1 - 4 } & & &
\end{tabular}

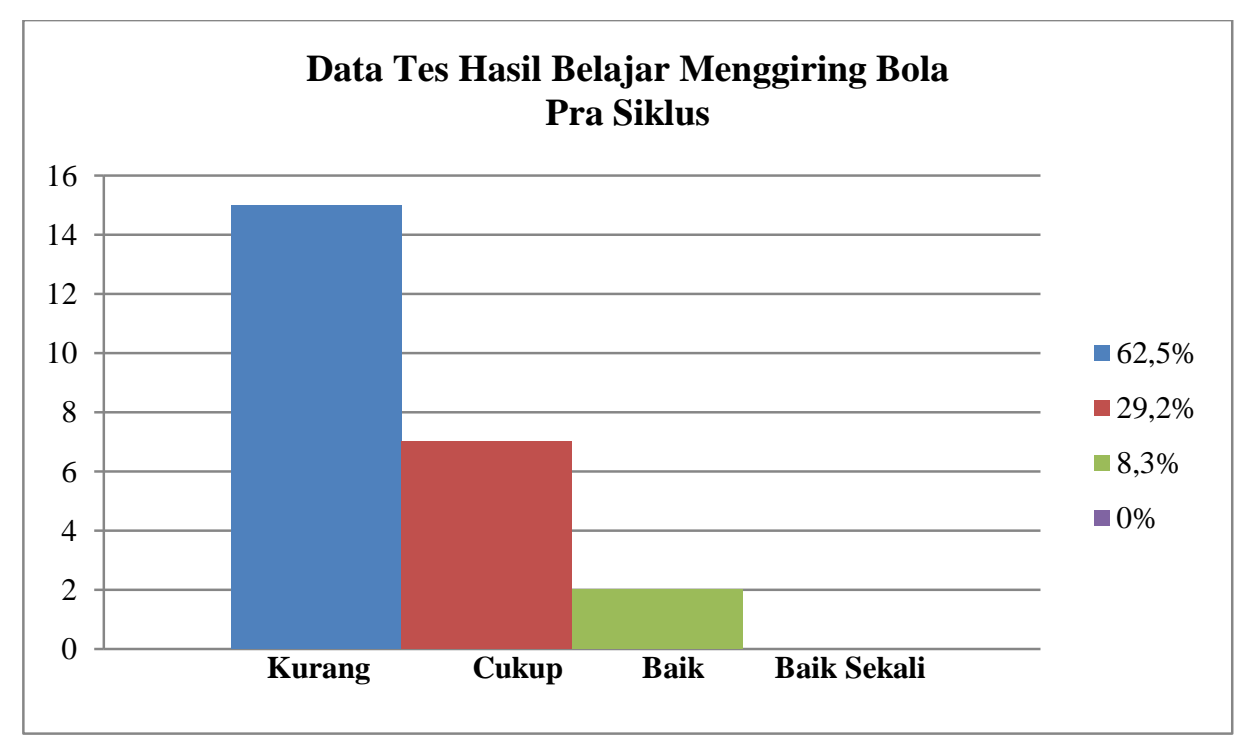

\section{Gambar 1 : Histogram Hasil Belajar Menggiring Bola Pra Siklus}

Berdasarkan data diatas maka dapat dilihat bahwa sebelum diberikan tindakan mayoritas siswa belum menunjukan hasil belajar cukup baik, dengan prosentase ketercapaian sebagai berikut : Kriteria Baik Sekali $=0 \%$, Baik $=$ $8,3 \%$, Cukup $=29,2 \%$, Kurang $=$ $62,5 \%$. Berdasarkan deskripsi data tersebut dapat disimpulkan baahwa tingkat keberhasilan pembelajaran yang diperoleh masih belum memuaskan. Untuk itu peneliti menyusun sebuah tindakan untuk meningkatkan kualitas pembelajaran materi menggiring bola dalam permainan sepak bola pada siswa di kelas tersebut.

\section{Siklus I}

$$
\text { Pada dasarnya }
$$

pembelajaran melalui pendekatan 
bermain cukup memberikan semangat kepada siswa dalam melakukan gerakan menggiring bola dalam permainan sepak bola, sehingga siswa lebih antusias dalam mengikuti pembelajaran, hal ini dapat diamati dari sikap yang awalnya khawatir dalam melakukan gerakan menggirirng bola, berubah menjadi suatu hal yang menyenangkan setelah menggunakan pendekatan bermain.

Namun bagitu, pada siklus I ini masih banyak kekurangan baik dalam proses pembelajarannya, maupun pada saat melakukan gerakan menggirimg bola. Hal tersebut dapat dibuktikan dari catatan kolaborator yang menyatakan, para siswa masih banyak yang kurang serius dalam melakukan setiap permainan, dan khususnya pada saat menggirirng bola, masih terdapat siswa yang pandangannya tetap terfokus terus pada bola, dan tidak memperhatikan situasi sekitar. Maka dari itulah, peneliti beranggapan hasil tersebut perlu ditingkatkan lagi, agar hasil belajar yang diperoleh dapat lebih optimal, dan siswa lebih dilibatkan lagi dalam interaksi pembelajaran sepak bola khususnya pada materi menggiring bola. Untuk itu, peneliti memutuskan untuk melanjutkan tindakan dalam pembelajaran melalui penerapan pendekatan bermain pada silkus II dengan permainan-permainan yang lain sesuai dengan kebutuhan siswa untuk meningkatkan hasil belajarnya.

Pada bagian ini penulis akan memaparkan tentang data hasil tes menggiring bola dalam permainan sepak bola. Berikut data hasil tes menggirirng bola dalam permainan sepak bola yang disajikan oleh penulis melalui tabel dan diagram dibawah ini : 
Didaktik : Jurnal Pendidikan, ISSN : 2477-5673, E-ISSN : 2614-722X

Sekolah Tinggi Keguruan dan IImu Pendidikan Subang Volume V Nomor 1, Juni 2019

Tabel 2 : Tes Hasil Belajar Menggiring Bola Siklus I

\begin{tabular}{|c|c|c|c|c|c|}
\hline No & $\begin{array}{r}\text { Rentang } \\
\text { Skor }\end{array}$ & Nilai & Frekuensi & Porsentase & Kategori \\
\hline 1 & $3-5$ & 60 & 6 & $25 \%$ & Kurang \\
\hline 2 & $6-8$ & 70 & 15 & $62,5 \%$ & Cukup \\
\hline 3 & $9-10$ & 80 & 2 & $8,3 \%$ & Baik \\
\hline 4 & $11-12$ & 90 & 1 & $4,2 \%$ & Baik Sekali \\
\hline \multicolumn{3}{|c|}{ Jumlah } & 24 & $100 \%$ & \\
\hline
\end{tabular}

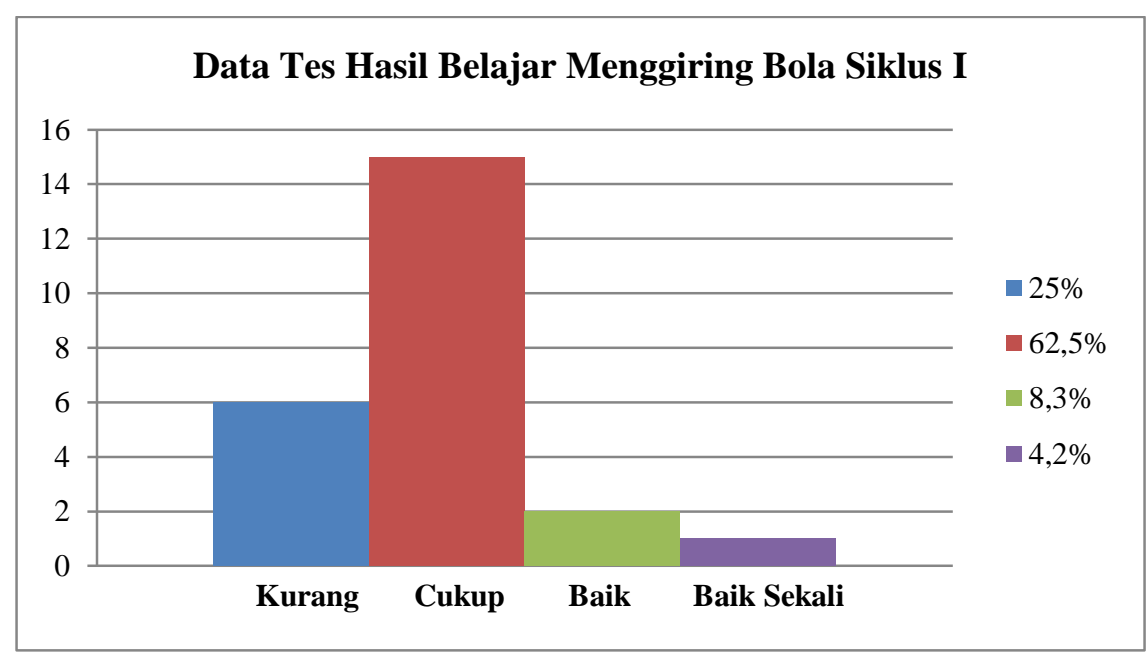

\section{Gambar 2 : Histogram Hasil Belajar Menggirirng Bola Siklus I}

Berdasarkan data tersebut diatas dapat dikemukakan hal-hal sebagai berikut: siswa yang berada pada kategori kurang dengan nilai 60 sebanyak 6 orang (25\%), siswa yang berada pada kategori cukup dengan nilai 70 sebanyak 15 orang $(62,5 \%)$, siswa yang berada pada kategori baik dengan 80 sebanyak 2 orang $(8,3 \%)$, dan siswa yang berada pada kategori baik sekali dengan nilai 90 ada 1 orang (4,2\%).

\section{Siklus II}

Berdasarkan hasil observasi yang telah dilakukan oleh peneliti dan kolabolator maka dapat disimpulkan pada siklus ke II siswa semakin antusias melakukan pembelajaran menggiring bola, tampak tidak ada ada kejenuhan 
dari siswa. Pada saat pembelajaran siswa nampak senang dengan metode pembelajaran yang diterapkan oleh guru. Pembelajaran menggiring bola melalui pendekatan bermain, siswa sudah mulai bisa menikmati pembelajaran, hal tersebut dikarenakan guru meancang suasana kelas menjadi suasana kompetisi. Hal ini terlihat dari sikap siswa yang cenderung selalu ingin mencoba lagi untuk melakukan gerakan menggiring bola.

Pada bagian ini, peneliti akan memaparkan data tes hasil menggiring bola dalam permainan sepak bola. Data tersebut peneliti akan sajikan dalam bentuk tabel dan diagram sebagai berikut :

\section{Tabel 3 : Tes Hasil Belajar Menggiring Bola Siklus II}

\begin{tabular}{|c|c|c|c|c|c|}
\hline No & $\begin{array}{c}\text { Rentang } \\
\text { Skor }\end{array}$ & Nilai & Frekuensi & Porsentase & Kategori \\
\hline 1 & $3-5$ & 60 & 3 & $12,5 \%$ & Kurang \\
\hline 2 & $6-8$ & 70 & 11 & $45,8 \%$ & Cukup \\
\hline 3 & $9-10$ & 80 & 7 & $29,2 \%$ & Baik \\
\hline 4 & $11-12$ & 90 & 3 & $12,5 \%$ & Baik Sekali \\
\hline \multicolumn{7}{|c|}{ Jumlah } & $\mathbf{2 4}$ & $\mathbf{1 0 0 \%}$ & \multicolumn{1}{c}{} \\
\cline { 1 - 2 } & & &
\end{tabular}

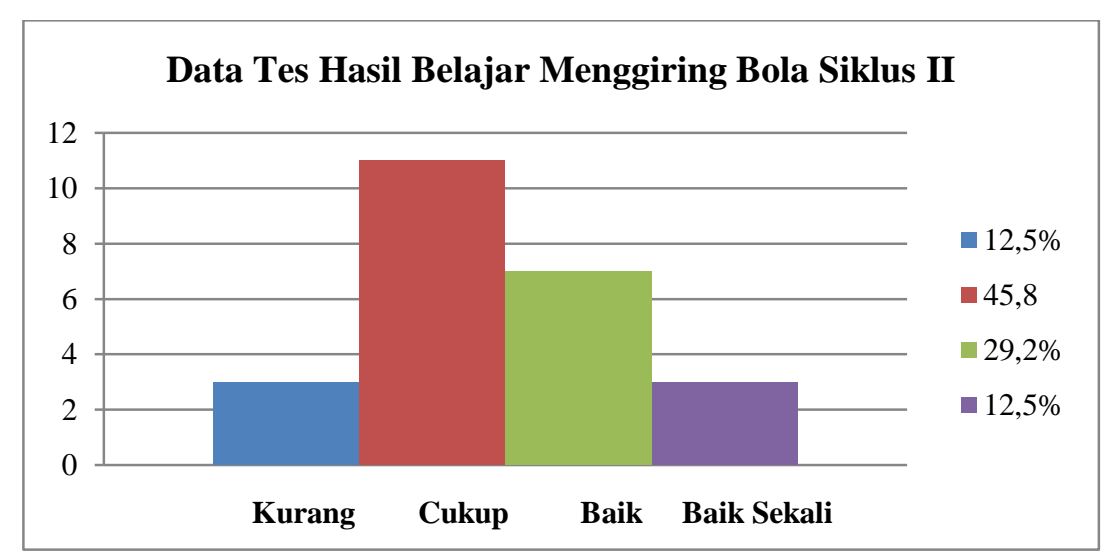

Gambar 3 : Histogram Hasil Belajar Menggiring Bola Siklus II 


\begin{abstract}
Berdasarkan data tersebut diatas dapat dikemukakan hal-hal sebagai berikut: siswa yang berada pada kategori kurang dengan nilai 60 sebanyak 3 orang (12,5\%), siswa yang berada pada kategori cukup dengan nilai 70 sebanyak 11 orang $(45,8 \%)$, siswa yang berada pada kategori baik dengan 80 sebanyak 7 orang $(29,2 \%)$, dan siswa yang berada pada kategori baik sekali dengan nilai 90 ada 3 orang $(12,5 \%)$.
\end{abstract}

Dengan begitu, maka dapat dikatakan bahwa pada siklus II penelitian telah mencapai target yang diinginkan yaitu secara keseluruhan $80 \%$ ketuntasan, dan pada siklus II ini siswa yang telah tuntas sebanyak $87,5 \%$, hal tersebut menunjukan penelitian ini sudah melebihi target yang diinginkan. Oleh karena itulah, peneliti berkeputusan tidak melanjutkan penelitian pada siklus berikutnya.

\section{Kesimpulan}

Berdasarkan hasil penelitian yang telah dilakukan, maka peneliti dapat menyimpulkan bahwa pendekatan bermain pada permaian sepak bola dapat meningkatkan hasil belajar menggiring bola pada siswa SDN Kertawaluya III Semester Genap Tahun Pelajaran 2014 / 2015. Penerapan Pendekatan bermain menggunakan alat yang sederhana dalam pembelajaran menggiring bola dalam permainan sepak bola merupakan salah satu alternatif dalam memecahkan beberapa masalah yang dihadapi guru dalam upaya mengaktifkan siswa dalam belajar. Oleh karena itu, guru harus mampu menciptakan kelas yang konduksif agar hubungan interaktif siswa dengan guru, siswa dengan siswa dapat terwujud dengan baik, sehingga suasana kelas menjadi aktif dan menarik.

\section{DAFTAR PUSTAKA}

Lutan, Rusli dan Suherman, Adang. (2000).

Perencanaan Pembelajaran Penjaskes. Jakarta: Depniknas.

Luxbache, A. Joseph. (2004). Sepak Bola. Jakarta: PT Raja Grafindo Persada Lengkong, Putra dan Dwi, Bintang. (2008). Games Seru Fun 
Didaktik : Jurnal Pendidikan, ISSN : 2477-5673, E-ISSN : 2614-722X

Sekolah Tinggi Keguruan dan IImu Pendidikan Subang Volume V Nomor 1, Juni 2019

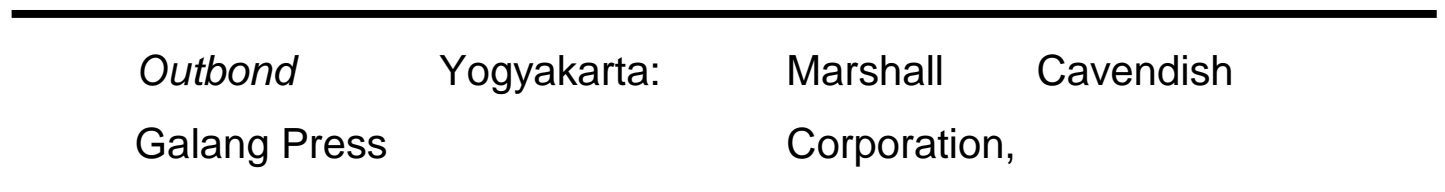

Miekle, Danny. (2003). Dasar -

Usli, W Lingling, (2011) dasar Sepak Bola. Eastrs Pembelajaran Sepak Bola Oregon University.

Cimahi: STKIP Pasundan

W Usli, Lingling. (2011). Cimahi,

Pembelajaran Sepak Bola.

Cimahi: STKIP Pasundan

Cimahi.

Soccer, USA: DK.

Publishing.

K. C. Kelley, (2009) Soccer, USA:

Koger ,Robert, (2007) Latihan

Cherry Lake Publishing.

Dasar Andal Sepak Bola

Hantula, Richad, (2012) Science at

Remaja terjemahan Arif

Work in Soccer, New York:

Subiyanto,Klaten: PT. Saka

Mitra Kompetensi 